\title{
Enhancement of SNUF Active Trailing-edge Flap Blade Mechanism Design
}

\author{
SNUF뒷전 플랩 블레이드 메커니즘의 설계 개선
Balakumaran Natarajan*, WonJong Eun* and SangJoon Shin ${ }^{\dagger}$
Balakumaran Natarajan-은 원 종·신 상 준

(Received March 14, 2013 ; Revised May 22, 2013 ; Accepted May 22, 2013)

Key Words : Active Trailing-edge Flap(능동형 뒷전플랩), Piezoelectric Actuator(압전작동기), Vibration Control (진동 제어), Active Rotor Blade(지능형 로터 블레이드)

\begin{abstract}
Seoul National University flap(SNUF) blade is a small-scale rotor blade incorporating a small trailing-edge flap control surface driven by piezoelectric actuators at higher harmonics for vibration attenuation. Initially, the blade was designed using two-dimensional cross-section analysis and geometrically exact one-dimensional beam analysis, and its material configuration was finalized. A flap-deflection angle of $\pm 4^{\circ}$ was established as the criterion for enhanced vibration reduction based on an earlier simulation. The flap-linkage mechanism was designed and static bench tests were conducted for verifying the performance of the flap-actuation mechanism. Different versions of test beds were developed and tested with the designed flap and the selected APA 200M piezoelectric actuators. Through significant improvements, a maximum deflection of $\pm 3.7^{\circ}$ was achieved. High-frequency experiments were conducted for evaluating the performance, and the transfer function of the test bed was determined experimentally. With the static tests almost complete, the rotor power required for testing the blade in a whirl tower (centrifugal environment) was calculated, and further preparations are underway.
\end{abstract}

\section{요 약}

SNUF(Seoul National University flap) 블레이드는 고주파 영역에서 진동 감쇠를 위하여, 압전작동 기에 의해 움직이는 뒷전 플랩이 장착되어 있는 축소형 로터 블레이드이다. 이 블레이드를 설계하기 위하여 2 차원 단면 해석과 1 차원 기하학적 정밀 보 해석이 수행되었고, 사용할 재료의 특성을 확인하 였다. 이전 연구자들의 실험을 참조하여, $\pm 4^{\circ}$ 의 플랩 변위각을 진동감쇠를 위한 설계요건으로 선정하 였다. 플랩의 연결 메커니즘을 설계하고, 설계된 메커니즘의 성능을 확인하기 위하여 정적 벤치 시험 을 수행하였다. 개선된 버전의 플랩 장치를 설계하고 시험하였으며, 압전작동기로는 APA $200 \mathrm{M}$ 을 선정

$\uparrow$ Corresponding Author; Member, School of Mechanical and Aerospace Engineering, and Institute of Advanced Aerospace Technology, Seoul National University

E-mail : ssjoon@snu.ac.kr

Tel : +82-2-880-1642, Fax : +82-2-887-2662

* School of Mechanical and Aerospace Engineering, Seoul National University

\# A part of this paper was presented at the KSNVE 2013 Annual Spring Conference

* Recommended by Editor SungSoo Na

(c) The Korean Society for Noise and Vibration Engineering 
하였다. 장비의 개선을 통하여, 최대 플랩변위가 $\pm 3.7^{\circ}$ 에 도달하였다. 성능을 평가하기 위하여 고주파 실험을 수행하였으며, 플랩 장치의 전달 함수를 실험적으로 결정하였다. 정적 시험을 완료하여, 훨타 워 시험을 위하여 필요한 로터의 요구마력을 계산하였고, 그 이외의 준비가 진행 중에 있다.

\section{Nomenclature}

\author{
$c_{d}$ : Drag coefficient of airfoil \\ $c_{l a}$ : Lift curve slope of airfoil \\ $v_{\beta}$ : Rotating flap frequency \\ $\mathrm{P}_{\mathrm{H}}:$ Hoverpower \\ $\mathrm{P}_{i}$ : Induced power \\ $\mathrm{P}_{\mathrm{o}}$ : Profile power \\ $\rho \quad$ : Local air density \\ $\sigma \quad$ : Rotor solidity
}

\section{Introduction}

In helicopters, among various sources of vibration such as the engine, transmission system, aerodynamic sources on the fuselage, and tail rotor, the prime source of vibration is the main rotor. High vibration levels are observed during forward and transition flights ${ }^{(1)}$. For better crew comfort, increased equipment life, and low maintenance and operating costs, the implementation of a vibration-reduction device is necessary.

Various passive devices ${ }^{(2)}$ are used for achieving vibration reduction. Simple mass/spring dynamic vibration absorption and isolation devices are used in helicopters such as Westland Lynx, Westland Seaking, Sikorsky Blackhawk, and Bell 206L Long Ranger helicopters. Large weight penalties and ineffectiveness over a wide range of flight conditions are some of the significant demerits of these passive techniques.

In addition to the passive methods, active vibration control is widely considered and implemented in rotorcrafts. The active twist rotor(ATR) and active trailing-edge flap(ATF) have been the most widely known approaches in recent years. In the ATR system $^{(3 \sim 5)}$, piezoelectric materi- als are embedded in the rotor blades or piezoceramic fibers are integrated with a resin matrix for creating an active fiber composite(AFC) material. On actuation, the system imposes a linear twist along the blade, thereby altering hub loads and reducing vibration. The AFC requires a very high input voltage(approximately 1,000 volts); however, it does not increase the profile drag unlike the ATF concept. Vibratory aerodynamic loads on the rotor can be countered using unsteady forces generated by actuating the rotor blades at higher harmonics of the rotor rotation frequency. The ATF method incorporates a small trailing edge flap that is used for altering the aerodynamics of the blade for achieving the desired vibration and/or noise reduction. It is generally installed at the outboard portion of the blade. Given that this system uses relatively compact electrical hardware to drive the flap, the required voltage input is small.

An experimental Eurocopter BK 117 helicopter $^{(6,7)}$ with piezoelectric driven trailing-edge flaps was the first to demonstrate vibration reduction through flight tests. The flight test started in 2005. Boeing's full-scale smart material-actuated rotor technology(SMART) rotor $^{(8,9)}$ based on the MD-900 rotor is another example of a popular full-scale rotor. The active blade concept(ABC) project by DLR, Germany, and ONERA, France ${ }^{(10)}$, and the smart hybrid active rotor control system(SHARCS) $)^{(11,12)}$ are a few of the model-scale rotors with piezostack-type-actuator-driven trailing-edge flaps.

The Seoul National University flap(SNUF) is an active rotor blade that uses the ATF method primarily for alleviating $\mathrm{N} / \mathrm{rev}$ hub vibratory loads in the hub-vertical direction. In this article, the bench experiments carried out for validating the flap mechanism and the preparations required for test- 
ing the blade in a whirl tower are discussed in detail.

\section{Blade Design and Tests}

\subsection{Design Configuration}

The SNUF blade is a small-scale articulated-type rotor blade based on the designs of SHARCS ${ }^{(11,12)}$ and NASA/ARMY/MIT active twist rotor(ATR) blades ${ }^{(4)}$. The ATR blade showed satisfactory vibration reduction performance during a test at NASA's Langley wind tunnel ${ }^{(5)}$ in a heavy gas environment. Therefore, its structural properties were selected as the target properties in the design of the present SNUF blade. However, the SNUF blade is planned to be tested in normal atmospheric conditions, and, hence, its rotation speed should be higher. The normal rotation speed of the ATR blade is 688 RPM, and that of the SNUF blade is 1,528 RPM. For matching the ATR blade's tip Mach number value of 0.6, the rotation speed of the SNUF blade was chosen as 1,528 RPM. The design configuration of the SNUF blade is described in Table 1.

\subsection{Cross-section and Spanwise Design}

For the SNUF blade, a single-spar configuration was chosen, similar to that of ATR blade. Due to non-availability of the materials used in the ATR

Table 1 SNUF design configuration

\begin{tabular}{c|c}
\hline \hline Rotor type & Articulated \\
\hline Rotor radius, $\mathrm{R}(\mathrm{cm})$ & 128 \\
\hline Rotation speed $(\mathrm{rpm})$ & 1,528 \\
\hline Blade chord, c $(\mathrm{cm})$ & 10.24 \\
\hline Hinge offset $(\mathrm{cm})$ & 5.12 \\
\hline Root cutout $(\%$ span $)$ & 20 \\
\hline Airfoil type & NACA0012 \\
\hline Tip mach number & 0.60 \\
\hline Lock number & 5.0 \\
\hline Mass per unit length $(\mathrm{kg} / \mathrm{m})$ & 0.55 \\
\hline Pretwist $($ deg $)$ & -10 \\
\hline Flap displacement & $\pm 4^{\circ}$
\end{tabular}

blade, the cross-section was designed using other available materials. In addition, the complicated front-spar configuration of ATR blade was replaced. The final design is shown in Fig. 1. The new design affords improved axial and flapwise bending stiffness ${ }^{(13)}$. A built-in linear twist distribution is chosen for the SNUF blade. Ballast weights(Table 2) are added in the nose region of the cross-section for maintaining the C.G. at $25 \%$ of the chord. The desired twist angle is $-10^{\circ}$. However, owing to the presence of the flap axis, no twist is applied in the flap-actuation region. The resulting built-in twist angle distribution is $-8^{\circ(13)}$.

\subsection{Mechanism Design and Tests}

The mechanism design depends mainly on the type of actuator selected. The block force should be sufficient for overcoming the moments due to aerodynamic, inertial, and centrifugal forces against flap deflection. In addition, the actuator should be compact for use with a small-scale blade. Considering these criteria, a piezostack-type APA 200M(14) actuator was selected. The width of the actuator was decreased from $7 \mathrm{~mm}$ to $5 \mathrm{~mm}$

Table 2 Ballast weight distribution

\begin{tabular}{|c|c|c|}
\hline Ballast weights & Ballast No & Weight/unit $\operatorname{span}(\mathrm{kg} / \mathrm{m})$ \\
\hline $2^{\circ}$ & 1 & 0.1959 \\
\hline 2 & 2 & 0.0667 \\
\hline
\end{tabular}

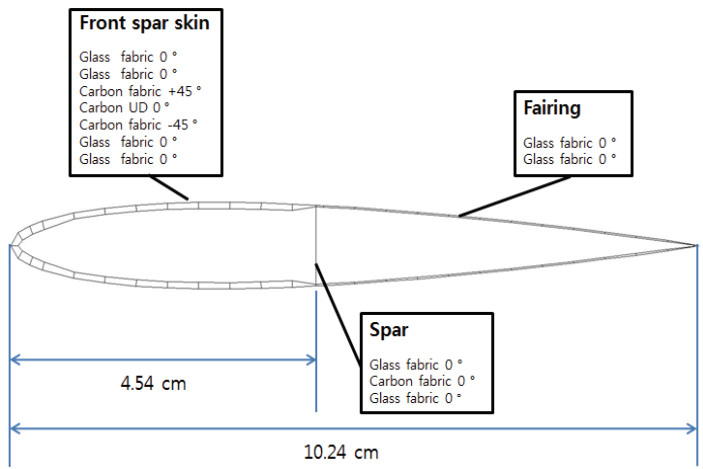

Fig. 1 SNUF cross-section design 
by the manufacturer given the requirements of the SNUF blade.

A schematic of the linkage mechanism for converting linear motion into rotary motion is shown in Fig. 2. An appropriate length $\left(\mathrm{L}_{2}\right)$ of the moment arm should be chosen for deflecting the flap to the desired angle against the externally acting flap hinge moment. The block force of the single APA 200M actuator is $73 \mathrm{~N}$. However, its free/maximum stroke is $0.23 \mathrm{~mm}$, according to the product specifications. Upon equating the force available(actuator block force) and the force required(force due to the aerodynamic hinge moment), it was found that the block force of a single actuator may not be sufficient for deflecting the flap under rotation. Therefore, it was concluded that multiple actuators would be required to achieve the required flap deflection.

The relationship between $L_{2}$ and the number of actuators was found to be non-linear. The appropriate values of $\mathrm{L}_{2}$ and the number of actuators are determined via a manual iterative process by examining the nonlinear relationship between the flap deflection and the moment arm length. Two actuators in a mechanically parallel configuration yielded a maximum flap deflection angle of $\pm 2.7^{\circ}$ for a hinge moment arm $\left(\mathrm{L}_{2}\right)$ of about $1.2 \mathrm{~mm}$. However, this is insufficient compared to the target value of $\pm 4^{\circ}$, and, therefore, the use of three actuators in parallel was considered. It resulted in a maximum flap deflection of $\pm 3.4^{\circ}$ for a moment arm length of about $0.9 \mathrm{~mm}$.

Initially, test beds with three and two actuators in parallel configuration were developed and tested. A deflection of $\pm 2.5^{\circ}$ with two actuators in

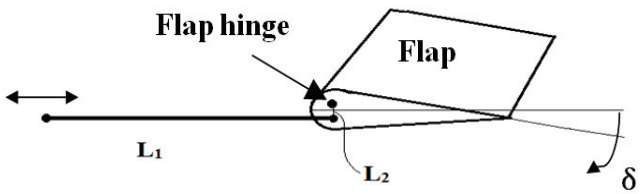

Fig. 2 Schematic of linkage mechanism the parallel configuration for a sinusoidal voltage input of $145 \mathrm{~V}$ at $1 \mathrm{~Hz}$ was achieved. Details of the two- and three-actuator configuration test results can be found in Ref. (13).

For further improving the design with the aim of enhancing deflection performance, the use of four actuators was decided upon. Two sets of actuators, each comprising two actuators connected in series, were connected in a mechanically parallel configuration. An analytical nonlinear prediction indicated a flap deflection of $\pm 3.9^{\circ}$ and hinge moment arm of $1.7 \mathrm{~mm}$ (Fig. 3). The current version of test bed(Fig. 4) incorporated the following two major changes:

(i) New flap design and flap horn owing to the increase in moment arm length $\mathrm{L}_{2}$.

(ii) An updated housing that integrates the separate fairing block and old housing design into a single unit.

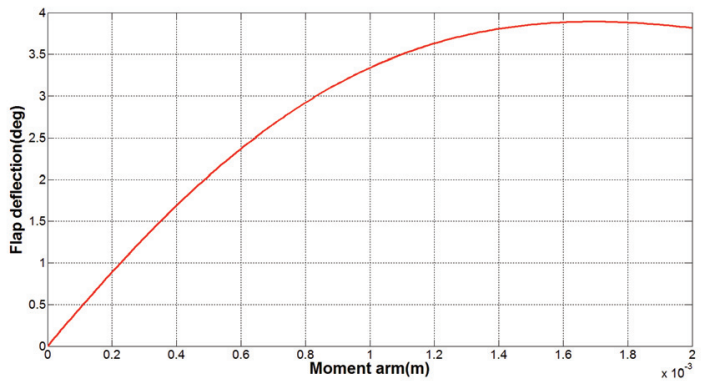

Fig. 3 Flap deflection vs. moment arm $\left(\mathrm{L}_{2}\right)$ relation when four actuators are used

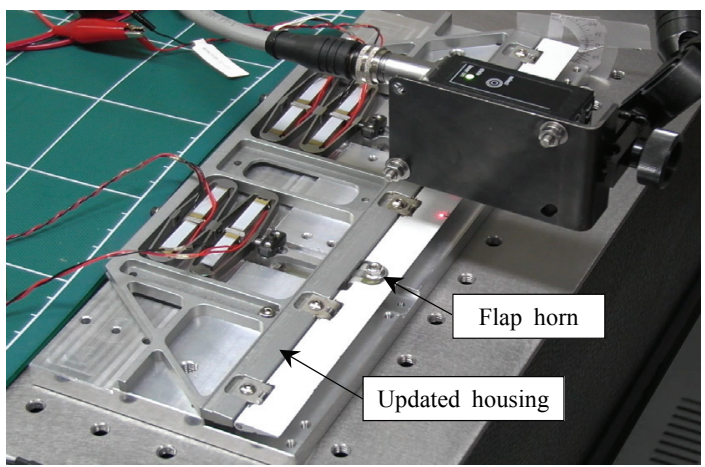

Fig. 4 Updated housing and flap with flap horn 
During initial tests, the four-actuator configuration performed worse than the two-actuator configuration. For the composite flap along with the hinge pins and sbrackets, it was found that during the process of curing, resin entered the space between hinge pins and hinge brackets, thereby preventing any rotation of hinge pins and increasing friction. After removing the resin, flap actuation tests were conducted, and a maximum flap deflection of $\pm 3.7^{\circ}$ (Fig. 5) was achieved at $142 \mathrm{~V}$ and $1 \mathrm{~Hz}$. The experimental results of other existing small-scale trailing-edge flaps and their actuation mechanisms from similar studies abroad are also summarized in Table 3.

\subsection{High-frequency Tests and Transfer Function}

Apart from the tests at $1 \mathrm{~Hz}$, the actuator should be able to provide sufficient stroke and block force at high frequencies of the order of $128 \mathrm{~Hz}(\sim 5 / \mathrm{rev}$ for SNUF) for achieving the desired vibration reduction performance. Tests were conducted in increments of $5 \mathrm{~Hz}$ up to $25 \mathrm{~Hz}$, and the results are shown in Fig. 6 .

For the version 4 test bed, the required power at $142 \mathrm{~V}$ for $1 \sim 25 \mathrm{~Hz}$ actuation was predicted to be as low as $0.63 \sim 15.8 \mathrm{~W}$. Variations can be observed in the flap-deflection amplitude with frequency. Moreover, a sudden decrease in the flap-deflection amplitude with time was observed at sustained high frequencies for the same input voltage. The reason for this abnormal behavior is under investigation.

To identify the transfer function ${ }^{(17)}$ of the flap mechanism, a swept sine signal was used as input (Fig. 7). It was a constant-amplitude sine wave signal of $140 \mathrm{~V}$, linearly increasing in frequency from $1 \mathrm{~Hz}$ to $25 \mathrm{~Hz}$ in a given time, followed by dwelling at $25 \mathrm{~Hz}$ for some time and returning to $1 \mathrm{~Hz}$. From the captured flap-deflection vector and input voltage vector(after amplification), the transfer function was estimated using tfestimate ${ }^{(18)}$ command in MATLAB. The transfer function of the flap mechanism was observed to be about $0.05^{\circ} \mathrm{V}$ (Fig. 8).

Table 3 Results of different test beds and the other researches

\begin{tabular}{c|c|c}
\hline \hline Version & Configuration & $\begin{array}{c}\text { Flap } \\
\text { deflection }\end{array}$ \\
\hline 1 & Single actuator & $\pm 2^{\circ}$ \\
\hline 2 & Two actuators in parallel & $\pm 1.5^{\circ}$ \\
\hline 3 & Three actuators in parallel & $\pm 2.5^{\circ}$ \\
\hline 4 & Four actuators in parallel & $\pm 3.7^{\circ}$ \\
\hline $\begin{array}{c}\text { Univ. of series } \\
\text { Maryland }\end{array}$ & 8-layer piezoelectric bender & $\pm 4^{\circ}$ \\
\hline $\begin{array}{c}\text { Univ. of } \\
\text { Michigan }\end{array}$ & C-block actuator & $\pm 5^{\circ}$ \\
\hline
\end{tabular}

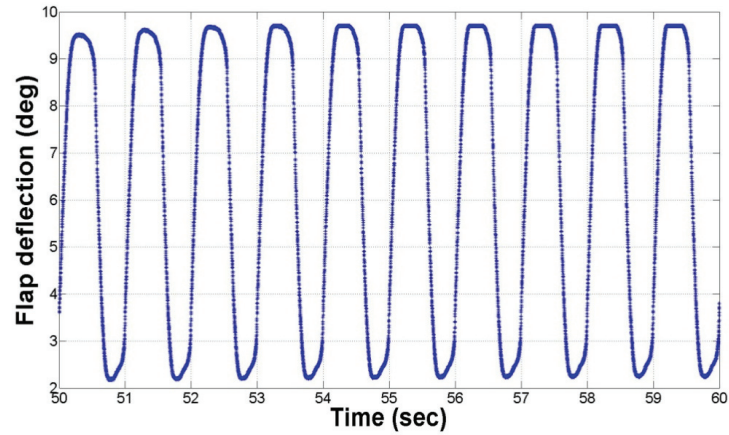

Fig. 5 Flap deflection for four-actuator $\left(142 \mathrm{~V}_{\mathrm{pk}-\mathrm{pk}}\right.$, $1 \mathrm{~Hz}$ ) configuration

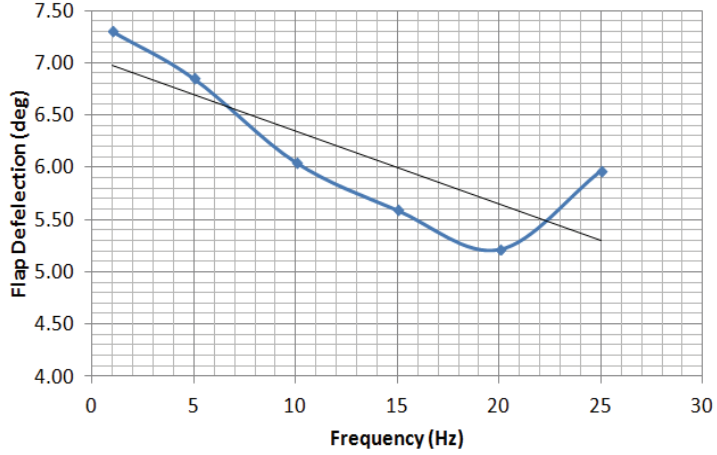

Fig. 6 Deflection vs. frequency(four actuators at $140 \mathrm{~V}$ ) 
Table 4 Parameters used for power estimation

\begin{tabular}{c|c}
\hline \hline Gross weight $(\mathrm{lb})$ & 450 \\
\hline Solidity, $\sigma$ & 0.102 \\
\hline Blade built-in twist $\left({ }^{\circ}\right)$ & -8 \\
\hline Tip speed (ft/s) & 669.3 \\
\hline Lift curve slope, $\mathrm{c}_{\mathrm{la}}$ & 6.3 \\
\hline Drag coefficient, $\mathrm{c}_{\mathrm{d}}$ & 0.01 \\
\hline Rotating flap frequency, $v_{\beta}$ & 1.03 \\
\hline Local air density, $\rho\left(\mathrm{lb} / \mathrm{ft}^{3}\right)$ & 0.00238 \\
\hline
\end{tabular}

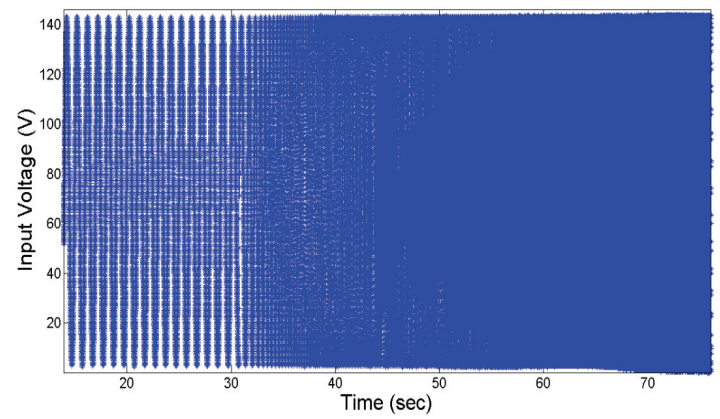

Fig. 7 Sine sweep input signal

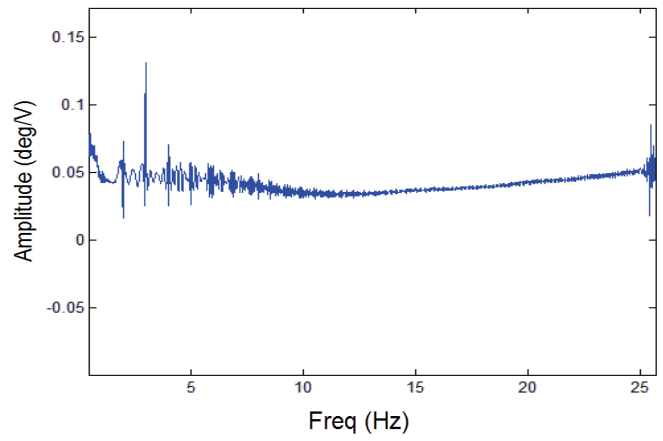

Fig. 8 Transfer function of flap mechanism

\section{Whirl Test Preparations}

\subsection{Power Estimation}

For conducting a whirl test of the rotor in an existing or new facility, estimation of the rotor torque and power is the prime step. In the case of hover ${ }^{(17)}$, the power required is composed into two important categories: profile power $\left(\mathrm{P}_{\mathrm{o}}\right)$ required to rotate or translate the rotor and induced

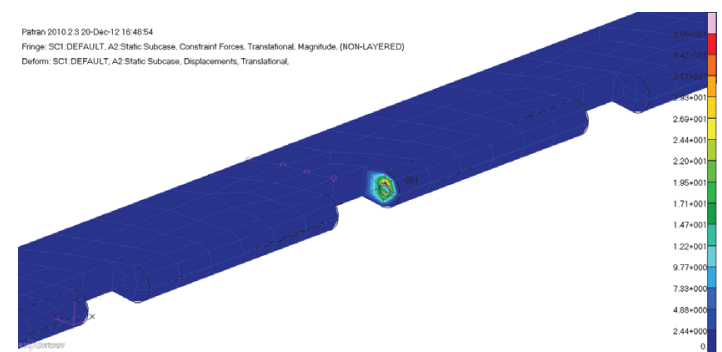

Fig. 9 Maximum constraint force at center

power $\left(\mathrm{P}_{\mathrm{i}}\right)$ needed to generate rotor thrust.

$$
\mathrm{P}_{\mathrm{H}}=\mathrm{P}_{\mathrm{o}}+\mathrm{P}_{\mathrm{i}}
$$

The profile power is a function of weight and the induced power is related to rotor drag. In our small-scale rotor design, which is not based on any helicopter, the gross weight is assumed as $450 \mathrm{lb}$ corresponding to the normal $\mathrm{C}_{\mathrm{T}} / \sigma$ value of 0.075 . The parameters used in the analysis are listed in Table 4, and the total hover power was found to be 48 H.P. using the procedure indicated in Ref. (19). While deciding the drive system power, losses need to be accounted for in addition to the predicted power.

\subsection{Design Improvements}

After completion of the flap bench tests, the blade design and instrumentation were finalized for the whirl tests. Regarding the blade design, a new improvement, i.e., the inclusion of a thrust bearing, was found to provide improved flap deflection ${ }^{(20)}$. Considering the larger magnitude of centrifugal loads, the maximum constraint forces acting on the flap support should be lower than the load rating of the thrust bearing. Thrust bearing F2-6 has a static load rating of $30 \mathrm{kgf}$ and a dynamic load rating of $16 \mathrm{kgf}^{(21)}$. Because the force gets distributed along the five flap hinge brackets(Fig. 4), a NASTRAN analysis was conducted to estimate the force distribution.

In the NASTRAN model, only the flap was modeled using QUAD4 elements. The material 


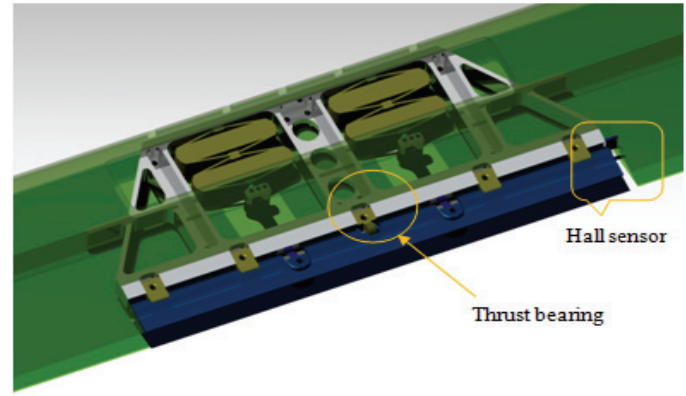

(a) Assembly

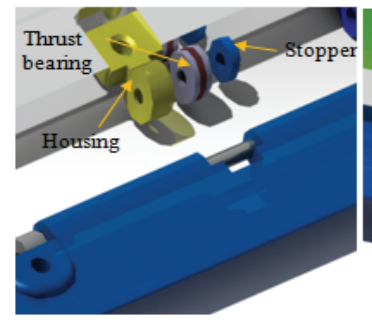

(b) Thrust bearing F2-6

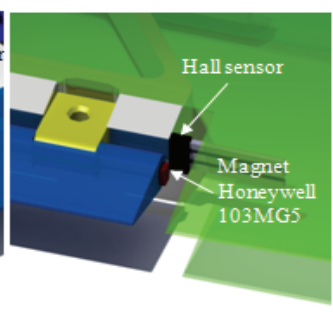

(c) Hall sensor
Honeywell SS495A1

Fig. 10 Thrust bearing and Hall effect sensor locations

properties of carbon UD and glass fabric were applied.

The total flap mass was around $10 \mathrm{~g}$, and a 0D mass element of $6 \mathrm{~g}$ was added at the flap c.g. to increase the flap mass to $16 \mathrm{~g}$. The $0 \mathrm{D}$ mass element was connected to the QUAD4 elements using RBE2 elements. Nodes in the holes that house the hinge pin were constrained along three translational and two rotational directions, allowing the pin to rotate in one direction. An RFORCE data card was used for applying the centrifugal force about the rotor center.

A linear static analysis was conducted by subjecting the flap to centrifugal forces. The maximum constraint force of $36.6 \mathrm{~N}(\sim 4 \mathrm{kgf})$ was observed at the center of the five hinge bracket locations(Fig. 9). Hence, thrust bearing F2-6 considered as being suitable for SNUF blade. Given the manufacturing complexities involved, only one thrust bearing was added at the middle hinge pin (Figs. 10(a) and (b)), the point at which the max- imum constraint forces were observed.

For the complete validation and load studies, the blade has to be carefully equipped with pressure sensors and strain gages at appropriate locations. However, during the initial whirl tests, it was decided that only the flap-deflection amplitude in a rotating environment would be checked. A laser sensor is currently being used for flap-deflection measurement in the static tests. For the rotary position sensing, Hall effect sensors are most commonly used. The Honeywell SS495A1 ${ }^{(10)}$ was considered based on its small size. The magnet was attached to the rotating flap, while the sensor on the housing in the inboard side(Fig. $10(\mathrm{c}))$.

\section{Conclusion}

In this paper, actuation tests conducted on the SNUF blade were discussed. Test beds, including the actual flap, were fabricated with different actuator configurations. It was understood that there should be minimum components between the actuators and the flap for minimizing the loss of actuation force, and high-precision manufacturing is required for achieving better flap performance. Flap deflection of $\pm 3.7^{\circ}$ was achieved with the four-actuator configuration. High frequency tests were conducted up to $25 \mathrm{~Hz}$, and sudden degradation of flap deflection was observed. For conducting a whirl tower test as the next step, the power requirement for rotor testing was estimated, and the design improvements implemented were presented.

\section{Acknowledgments}

This work was partly supported by a National Research Foundation of Korea(NRF) grant funded by the Korean Government(2011-0029094) and financially by Korea Ministry of Land, Transport and Maritime Affairs under the "Haneul Project". 


\section{References}

(1) Johnson, W., 1994, Helicopter Theory, Chap. 12, Dover Publications, Inc., N.Y.

(2) Newman, S., 1994, The Foundations of Helicopter Flight, Chap. 10, E. A., Great Britain.

(3) Roget, B., 2004, Individual Blade Control of Vibration Reduction of a Helicopter with Dissimilar Blades, Ph.D. Thesis, Chap. 1, Dept. of Aerospace Engineering, University of Maryland.

(4) Shin, S. -J., Cesnik, C. E. S. and Hall, S. R., 2007, Design and Simulation of Integral Twist Control for Helicopter Vibration Reduction, International Journal of Control, Automation, and Systems, Vol. 5, No. 1, pp. 24 34.

(5) Wilbur, M. L., Mirick, P. H., Yeager, W. T., Jr., Langston, C. W., Cesnik, C. E. S. and Shin, S. J., 2002, Vibratory Loads Reduction Testing of the NASA/Army/MIT Active Twist Rotor, Journal of the American Helicopter Society, Vol. 47, No. 2, pp. 123 133.

(6) Roth, D., Enenkl, B. and Dieterich, O., 2006, Active Rotor Control by Flaps for Vibration ReductionFull Scale Demonstrator and First Flight Test Results, 32nd European Rotorcraft Forum, The Netherlands.

(7) Konstanzer, P., Enenkl, B., Aubourg, P.-A. and Cranga, P., 2008, Recent Advances in Eurocopter's Passive and Active Vibration Control, 64th AHS Annual Forum, Montreal, Canada.

(8) Straub, F., Anand, V., Birchette, T. and Lau, B., 2009, SMART Rotor Development and Wind-Tunnel Test, 35th European Rotorcraft Forum, Hamburg, Germany.

(9) Kottapalli, S., 2011, Enhanced Correlation of SMART Active Flap Rotor Loads, 52nd AIAA/ASME/ASCE/AHS/ASC Structures, Structural Dynamics and Materials Conference, Denver, Colorado.

(10) Mainz, H., van der Wall, B. G., Leconte, P., Ternoy, F. and des Rochettes, H. M., 2005, ABC Rotor Blades: Design, Manufacturing and Testing, 31st European Rotorcraft Forum, Florence, Italy.

(11) Feszty, D., Nitzsche, F., Khomutov, K., Lynch, B. K., Mander, A. and Ulker, F. D., 2008, Design and
Instrumentation of the SHARCS Scaled Rotor with Three Independent Control Systems, American Helicopter Society 64th Annual Forum, Montreal, Canada.

(12) Feszty, D. and Nitzsche, F., 2011, Review of Active Rotor Control Research in Canada, Int. Journal of Aeronautical and Space Sciences, Vol. 12, No. 2, pp. 93 114.

(13) Balakumaran, N., Eun, W.-J., Lee, J.-H. and Shin, S.-J., 2012, Structural Design of an Active Trailing-Edge Flap Blade for Helicopter Vibration Control, Proceedings of the 53rd AIAA/ASME/ASCE/ AHS/ASC Structures, Structural Dynamics and Materials Conference-Adaptive Structures Forum, Honolulu, Hawaii, USA.

(14) http://www.cedrat-technologies.com/(accessed $11 / 2012)$

(15) Koratkar, N. A. and Chopra, I., 2002, Wind Tunnel Testing of a Smart Rotor Model with Trailing-edge Flaps, Journal of the American Helicopter Society, Vol. 47, No. 4, pp. 263 272.

(16) Clement, J. W., Brei, D. and Barrett, R., 1999, Wind Tunnel Testing of a High Authority Airspeed Insensitive Rotor Blade Flap, 40th AIAA/ASME/ASCE/ AHS/ASC Structures, Structural Dynamics, and Materials Conference and Exhibit, St. Louis, MO, USA.

(17) Prechtl, E. F., 2000, Design and Imple-mentation of a Piezoelectric Servo-flap Actuation System for Helicopter Rotor Individual Blade Control, Ph.D. Thesis, Chap. 4, Dept. of Aeronautics and Astronautics, MIT.

(18) http://www.mathworks.co.kr/kr/help/signal/ref/ tfestimate.html(accessed 02/2013)

(19) Laxman, V., Lim, J. H., Shin, S. J., Ko, K. H. and Jung, S. N., 2011, Power and Trim Estimation for Helicopter Sizing and Performance Analysis, Int'l Journal of Aeronautical and Space Science, Vol. 12, No. 2, pp. 156 162.

(20) Koratkar, N. A. and Chopra, I., 1999, Design, Fabrication and Testing of a Mach Scaled Rotor Model with Trailing-Edge Flaps, American Helicopter Society 55th Annual Forum, Montreal, Canada.

(21) http://www.astbearings.com/product.html? product =F2-6 (accessed 11/2012)

(21) Lee, J.-H., Kim, T.-S. and Shin, S.-J., 2009, Design of an Intelligent Rotor with Flap for Vibration 
Reduction in Helicopters, Proceedings of the KSNVE Annual Spring Conference, pp. 460 461.

(22) Lee, J.-H., Choe, J.-H. and Shin, S.-J., 2011, Development of an Intelligent Active Trailing-edge Flap Rotor to Reduce Vibratory Loads in Helicopter, Proceedings of the KSNVE Annual Spring Conference pp. 492 497.

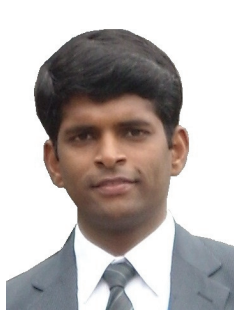

Balakumaran Natarajan received his Bachelor's degree in Aeronautical Engineering from MIT, Anna University, India, in 2007. $\mathrm{He}$ worked with the Helicopter Division of Hindustan Aeronautics Limited in the Design Liaison Engineering Dept. during 2007 2011. He received his MS degree from Seoul National University in 2013. His research interests include finite element analysis, and wind turbine and helicopter rotor blade design.

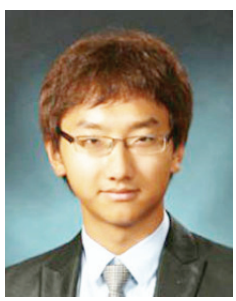

WonJong Eun received his BS in mechanical and aerospace engineering from Seoul National University, Seoul, Korea, in 2012. During 2007 2009, he worked as a Korean Army helicopter crewmember at UH-60 AVN. Mr. Eun is currently in a MS course at the Active
Aeroelasticity and Rotorcraft Laboratory, Seoul National University. His research interests include multibody dynamics, rotorcraft dynamics, and structure dynamics.

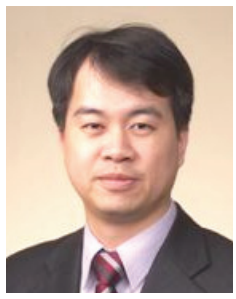

SangJoon Shin received SM and $\mathrm{PhD}$ degrees in Aeronautics and Astronautics from Massachusetts Institute of Technology in 1999 and 2001, respectively. During 1991 1996, he worked at the Helicopter Systems Department, Korean Agency for Defense Development. During 2001 2003, he worked at the Department of Aerospace Engineering, University of Michigan, Ann Arbor. Since 2003, he has been a professor at the School of Mechanical and Aerospace Engineering, Seoul National University. His research interests include aeroelasticty, rotorcraft dynamics, and smart structures. 